\title{
Entrance Skin Dose (Radiation) Measurement and Evaluation (for all age groups) at the State Specialist Hospital, Okitipupa, Nigeria
}

\author{
Gilbert Ibitola, Abiola Olawale Ilori*, Olanrewaju Ajanaku, Reuben \\ Dapo Utomewore
}

Ondo State University of Science and Technology, Okitipupa, Nigeria

* Corresponding author: Abiola Olawale Ilori: iloriabiola99@gmail.com

\section{OPEN ACCESS}

Citation: Ibitola G., Ilori A.O., Ajanaku O., Utomewore R.D. (2018) Entrance Skin Dose ( Radiation) Measurement and Evaluation ( for all age group) at the State Specialist Hospital, Okitipupa, Nigeria. Open Science Journal 3(2)

Received: $2^{\text {nd }}$ April 2018

Accepted: $21^{\text {st }}$ May 2018

Published: $18^{\text {th }}$ June 2018

Copyright: @ 2018 This is an open access article under the terms of the Creative Commons Attribution License, which permits unrestricted use, distribution, and reproduction in any medium, provided the original author and source are credited.

Funding: The author(s) received no specific funding for this work

Competing Interests: The author have declared that no competing interests exists.

\section{Abstract:}

This study was carried out on entrance skin dose (ESD) (Radiation) measurement and evaluation (for all age groups) at the State Specialist Hospital, Okitipupa, Ondo State, Nigeria. Entrance skin doses for randomly selected patients between 0-4 years, 5-9 years, 1017 years and above 18 years old undergoing X-ray chest (Poster Anterior) examinations were measured and evaluation of the sourceto-skin distance (SSD) records for the patients during the x-ray chest examinations were carried out. The mean ESD reported for chest PA projections were $66.43 \mu \mathrm{Gy}, 105.10 \mu \mathrm{Gy}, 215.76 \mu \mathrm{Gy}$ and $291.81 \mu \mathrm{Gy}$ respectively for age ranges 0 - 4 years, 5 - 9 years, 10 - 17 years and above 18 years. The ESD values reported in this present study were same with the NRPB recommendations of year 2000 of $50 \mu \mathrm{Gy}$ for newborn to 1-year-old, $70 \mu \mathrm{Gy}$ for 5 years and $120 \mu \mathrm{Gy}$ for 10 years old children. The values reported for age 1 to 4 years were lower than $0.1 \mathrm{mGy}$ recommended and the mean ESD for age 5 to 9 years for chest PA examination was $0.11 \mathrm{mGy}$ which is lower than the recommended $0.12 \mathrm{mGy}$. However, other values reported in this present study were compared with the guidance levels set by the International regulation bodies and were found to be within safe limits and they do not pose any significant health risk to the patients of all age ranges or the health workers. The effective radiation doses (ERDs) for all the age groups were computed, and by comparisons, it was found that the radiation risk factors (RRFs) are relatively low. 
Keywords: Entrance skin dose (ESD), X-ray, Chest (Poster Anterior) examination, FSD, BSF, Safe limits, National Radiation Protection Board (NRPB), Radiation, Nigeria.

\section{Introduction}

The application of medical imaging in medical procedures has led to improvements during diagnosis and treatment of numerous medical conditions in children and adults. There are many modalities of medical imaging procedures, each of which uses different technologies and techniques. Medical imaging which includes computed tomography $(\mathrm{CT})$, fluoroscopy and radiography (conventional $\mathrm{X}$-ray); all make use of ionizing radiation to generate images of the body. Ionizing radiation is a form of radiation that has enough energy to potentially cause damage to DNA and may elevate a person's lifetime risk of developing cancer [7]. Radiation safety, monitoring and assessment have now become issues of great concern, since at high doses, its effects to humans are numerous.

Medical uses of ionizing radiation now contribute above $95 \%$ of man-made exposure to radiation, this now ranks only second to natural background radiation [12]. Also, computed tomography (X-ray machines) which has dose modality has become more available in many developing nations such as Nigeria and about 3.6 billion imaging studies per year are carried out world-wide, leading to increase of $70 \%$ in worldwide collective effective dose for medical diagnostics procedures [8]. Improvements on designs of X-ray machines and X-ray facilities have led to drastic reductions in personnel doses in the last two decades, this is not same to patients [10]. Any radiation protection practice should be justified by weighing the potential harm against perceived benefit [9]. It has been suggested that minimum amount of X-ray radiation should be used during X-ray examination to minimize its effect and the entrance skin dose should be measured and monitored. Dose is greatest at the surface where radiation enters the body of the patient and the skin is therefore the main organ for which there is a possibility of deterministic effect such as skin burn.

In Nigeria and many other parts of the world, medical fitness examinations which often include X-ray examinations are requested either at the point of admission into higher institutions, job employments, or during treatment of one ailment or the other. Chest radiographs are used to screen for job related lung disease such as mining where workers are exposed to dusts. Millions of X-ray examinations are undergone at every point in time all through the year by people thereby increasing the exposure to ionizing radiation. Chest radiography is the most common of all X-ray examinations. Chest radiography, commonly chest Xray, is a projection radiograph of the chest used to diagnose condition affecting the chests, its contents and nearby structure. Chest radiographs are the most common examinations taken as a therapeutic tool for many clinical conditions such as pneumonia and congestive heart failure.

Several hospitals across Nigeria contribute certain varying doses of ionizing radiation to the existing background naturally occurring radiation in the environment. In Okitipupa, the state specialist hospital attends to hundreds of patients in need of X-ray examinations weekly both from the rural and urban settlements. In most rural areas surrounding Okitipupa, there is no adequate 
medical facilities to cater for the population. This makes many people in need of medical examinations and treatment flux into the state specialist hospital in Okitipupa for proper medical examination and treatment. Therefore, it is necessary to measure the entrance skin dose from Chest X-ray diagnosis of patients at the state specialist hospital in the study area.

Entrance skin dose is used in plain radiography to set diagnostic reference levels, a reference level that establishes a benchmark for the optimization in using medical radiation, ensuring that departments adhere to the principles and practice of radiation protection [2]. The aim of the present study is to measure the entrance skin dose for patients undergoing chest X-ray examinations at the state specialist hospital in Okitipupa with the objectives to measure source-toskin distance (SSD) for each patient during the x-ray chest examination, estimate the entrance skin dose of patients between 0-4 years, 5-9 years, 10-17 years and above 18 years during X-ray chest (Poster Anterior) examinations and compare the doses measured with the international reference doses reported in other literatures.

\section{Materials and Methods}

\section{General Principles}

Radiation interacts with the materials of the detector and energy is deposited within it.

The deposited energy produces:

electron-ion pairs in gases and plastics;

electron-hole pairs in semiconductors and plastics;

excitation of molecules and atoms in materials and living tissues;

damage (if the dose is too high) to the materials or living tissues.

Radiation is measured by:

The collection of free charge(s) in ionization chambers and semiconductor detectors;

The observation of visible light emitted when molecules and atoms decay in the

material or living tissue - scintillation counters;

Development of a latent image in photographic emulsions:

tracks of energetic particles;

general darkening by X-ray.

To counting of damage tracks in plastics.

There are mainly two types of radiation detection, namely: (i) static detection and (ii)

dynamic detection.

Static detection: Particles striking photographic film cause 'tracks' which can be enhanced by chemical development. The effective charge and the mass of the radiation can be estimated from the ionization density $(\mathrm{dE} / \mathrm{dx}$ ) along the track. Similar 'track' or damage effects can occur in materials or in living tissues in which the energy can be stored. For example, in their moluminescent dosimeters, 
radiation impinges on a phosphor which emits light when it is subsequently heated under controlled conditions. The integrated light emission is a measure of the radiation dose to which the material or living tissue has been exposed.

Dynamic detection: The radiation (such as X-ray) causes ionization in a gas, material or living tissue with the creation of ion-electron or electron-hole pairs. These charges can be detected directly (in an ionization chamber, a proportional counter, Geiger-Mueller counter or semiconductor detector), or be observed through light emitted when the electron-hole pairs recombine (a scintillation detector), or measured directly by a dosimeter or radiation intensity meter.

Radiation Dose Equivalent $\mathrm{H}=$ Radiation Dose (D) X Quality factor (Q) (in Sievert

(1)

$$
\begin{aligned}
& \text { Radiation Dose Equivalent Rate }=d H / d t \\
& \mathrm{H}=d D / d t \mathrm{X} \mathrm{Q}(\mathrm{Sv} / \mathrm{hr} \text { or } \mathrm{mSv} / \mathrm{a})
\end{aligned}
$$

Absorbed dose rate $\left(D^{*}\right)$, for X-ray, is: $D^{*}=\frac{d D}{d t}(\mathrm{~Gy} / \mathrm{a}$ or $\mathrm{Gy} / \mathrm{hr})$.

The exposure $(\mathrm{X})$ to a radiation field of $\mathrm{X}$-rays is measured by the number of ions produced per unit mass of dry air.

(4)

$$
\mathrm{X}=\Delta \mathrm{q} / \Delta \mathrm{m}(\mathrm{c} / \mathrm{kg}) .
$$

The absorption of X-rays of energy $\mathrm{E}$ and flux $I_{0}$ photons $/ \mathrm{cm}^{2} / \mathrm{s}$ falling on the surface of a medium or living tissue is determined by the absorption coefficient $\mu a(E)$. The amount of radiation that is absorbed by a body (living or non-living) is determined by its size L (in this present case, the chest thickness) relative to the absorption length for the radiation $\left(1 / \mu_{a}\right)$.

For X-rays, where $L \geq\left(1 / \mu_{a}\right)$, we have:

$$
\begin{aligned}
& I_{(\text {absorbsd })}=\int_{0}^{L} I(0) e^{-\mu x} d x \\
& =\frac{I(0)}{\mu_{a}}\left(1-e^{-\mu L}\right.
\end{aligned}
$$

In radiation protection, the important physical quantity is the dose rate $d D / d t$ to biological (living) tissue. For living tissues, the radiation dose equivalent rate is:

$$
\frac{d H}{d t}=5.76 \times 10^{-4} Q \cdot I(0) \cdot E \cdot\left(\frac{\mu_{a}(E)}{\rho}\right)_{\text {tissue }}(\text { in } \mathrm{mSv} / \mathrm{hr})
$$

The total radiation dose after time $\mathrm{T}$ to a living organ from a source of initial strength $\mathrm{C}(0)$ which decays as:

$$
C(t)=C(0) \cdot \mathrm{e}^{-\lambda \mathrm{t}},
$$

Is expressed as:

$$
\begin{aligned}
& H=\int_{0}^{T}(d H / d t) e^{-\lambda_{\text {eff }} t} d t \\
& ==\frac{1.38 \times 10^{-5} C(0) \cdot \xi \cdot Q\left(1-\theta^{-\lambda t}\right)(S v)}{m \cdot \lambda_{\text {eff }}}
\end{aligned}
$$


Where:

$\lambda_{\text {sff }}=0.693 / T_{\frac{1}{2}}\left(\right.$ day $\left.^{-1}\right)$;

$m=$ mass $(\mathrm{kg})$ of the living tissue;

$\xi=\sum_{i-1}^{N} f_{i} F_{i} Q_{i} E_{i}$

$f_{i}=$ fraction of $\mathrm{X}$-ray radiation emitted of type $i$;

$F_{i}=$ fraction of radiation retained within the living organ;

$Q_{i}=$ quality factor for the $i^{\text {th }}$ component;

$E_{i}=$ energy in $\mathrm{meV}$.

Please refer to tables A1, A2 and A3 in the Appendix for standard records on radiation permitted limits, maximum permissible doses, and on clinical effects of acute radiation doses.

\section{Materials}

The study is carried out using the x-ray facilities at the Radiology Department of the State Specialist Hospital, Okitipupa with the operator attached to a collecting and reading Thermo-Luminous Dosimeter (TLD). Protective barriers shielding requirement for personnel and public were available at the sampled hospital where estimated data were generated. The x-ray machine facility at the specialist hospital was used to allow wider coverage of frequencies. Initially, questionnaires were distributed to the radiographers in charge of the diagnostic facilities. Information of the manufacturer, model, year of installation and other x-ray exposure parameters were obtained. The Entrance Skin Dose was assessed by indirect method, with the use of data on the radiation output of the $\mathrm{X}$-ray tubes and exposure factors.

\section{Methods}

\section{Reading of TLD to obtain transmitted doses}

Technique factors such as KVp, mAs, film-to-skin distance (FSD), focus-tofilm distance (FFD), film size and patients' features such as weight, height, age and thickness of the radiated region were obtained for the chest (Poster Anterior) examinations. The measurements were carried out during the routine checkup examinations of the patients with the assistance of the radiology unit staff which include radiographers and dark-room technicians. The patients were divided into four age groups: 0-4 years, 5-9 years, 10-17 years, above 18 years, a total of 60 (sixty) patients were randomly selected during the examinations. Survey meter was used to measure the output of the X-ray machine. All radiographic films were found to be diagnostically acceptable by the radiologist in charge of the unit. The source-to-skin distance (SSD) was obtained for each patient using the focal-to-film distance (FFD) and the thickness of the patient's chest6.

$S S D=F F D-$ thickness of the patient's che

During the examination, the patient stands facing the erect Bucky with the chest in contact with the Bucky, the arms placed on both sides of the hips with 
the shoulder rolled forward, this is to displace the scapulae from the lungs field. The output of the X-ray tube at $80 \mathrm{KVp}$ was measured using calibrated $\mathrm{KVp}$ and the output value was found to be $0.03017 \mathrm{mGy}\left(\mathrm{mAs}^{-1}\right)$; BSF is 1.35 , the tube number is 40D423; housing number B006E; filtration 1.5 AL and TLD dimensions: $76 \times 76 \mathrm{~mm}$.

\section{Entrance skin dose (ESD)}

The entrance skin dose is the measure of the radiation dose that is absorbed (mGy) by the skin as it reaches the patient. ESD is a directly measurable quantity, often, measured using thermos-luminescent dosimeters [6]. ESD is often a benchmark measurement used to assist in quality control and optimization in radiography departments, it is the maximum amount of x-radiation absorbed by living tissues during medical examinations. The dose to a patient was determined by calculating from the x-ray tube parameters and exposure radiographic parameters [4]. The entrance skin dose formula is given as:

Entrance skin dose $=$ Tube Output $x\left(\frac{K V p}{80}\right)^{2} x\left(\frac{100}{F S D}\right)^{2} x m A s x B S F$

Where FSD is the film-to-skin distance, KVp is the peak voltage responsible for the quality of penetration; $\mathrm{mAs}$ is the tube current responsible for quantity of electrons from the filament. BSF is a back scatter factor for a particular examination at the required potential and was taken as 1.35 [11].

The entrance skin dose recommendations for an adult of average size (70-80 $\mathrm{kg}$ ) in chest examination is $0.2 \mathrm{mGy}$ for chest PA and $1.0 \mathrm{mGy}$ for chest lateral2. Factors that contribute to an increase in entrance skin dose include body habitus (obese patients can have a dose increase reaching factors of 80) and poor radiographic positioning [3].

\section{Results and Discussions}

The results of Entrance Skin Dose (ESD) for Chest Radiological Examination (Poster Anterior) for different age groups (0-4 years, 5-9 years, 10-17 years and above 18 years old respectively) were obtained and tabulated. Tables 1-4 contained the values of $\mathrm{KVp}$, mAs, FFD, FSD, weight, Height and SSD which were collected from the radiological department of the State Specialist Hospital, Okitipupa. A total of 60 patients were randomly selected, i.e., 15 patients for each age group respectively.

The results were presented in Tables 1 - 4. There was wide variation in technical parameters (KVp and mAs) used in this hospital when compared with the values reported for other works which shows that there is no standard procedure. In this present study, mAs vary from $6.50-12.50 \mathrm{mAs}$ in age range 04 years; $12.50-15.00 \mathrm{mAs}$ in age range 5-9 years, $16.00-20.00 \mathrm{mAs}$ in age range 10-17 years and $16.00-22.50 \mathrm{mAs}$ in age above 18 years for chest PA respectively.

The ranges and means of the results of the chest PA examinations for the four age groups were presented. The range of dose for chest PA projection for age range 0-4 years was $38.90-88.39 \mu \mathrm{Gy}$ with a mean value of $66.43 \mu \mathrm{Gy}$; for age range 5 - 9 years, the range was $99.00-115.47 \mu \mathrm{Gy}$ with a mean value of 105.10 $\mu \mathrm{Gy}$; for age range 10-17 years, the range was $162.92-277.19 \mu \mathrm{Gy}$ with a mean 
value of $215.76 \mu \mathrm{Gy}$ and for age range above 18 years, the range was 183.28 $515.48 \mu \mathrm{Gy}$ with a mean value of $291.81 \mu \mathrm{Gy}$. The doses reported for this present study were lower when compared to the reported values of 84-159 $\mu \mathrm{Gy}$ with a mean of $111 \mu \mathrm{Gy}$ for age 1-5 years, 145 - $165 \mu \mathrm{Gy}$ with a mean of $159 \mu \mathrm{Gy}$ for age 5 - 10 years and $280-1590 \mu \mathrm{Gy}$ with a mean of $620 \mu \mathrm{Gy}$ for age 10-15 years respectively1.However, the values reported in this present study were same with the NRPB recommendations of year 2000 of $50 \mu \mathrm{Gy}$ for new borns to 1-year-old, $70 \mu \mathrm{Gy}$ for 5 years and $120 \mu \mathrm{Gy}$ for 10 years old children. The values reported for age 1-4 years were lower than $0.1 \mathrm{mGy}$ recommended5 and the mean ESD for age group 5-9 years for chest PA examination was $0.11 \mathrm{mGy}$ which is lower than the recommended $0.12 \mathrm{mGy}$ [11]. The range of tube potential for all projections is $46-90 \mathrm{kV}$.

Table 1: Results of Chest examination (PA) for 0-4 years

\begin{tabular}{ccccccccccc} 
S/N & Weight $(\mathrm{kg})$ & Height $(\mathrm{cm})$ & KVp & FSD $(\mathrm{m})$ & mAs & FFD $(\mathrm{cm})$ & Thickness $(\mathrm{cm})$ & SSD $(\mathrm{cm})$ & ESD $(\mathrm{mGy})$ & ESD $(\mu \mathrm{Gy})$ \\
\hline 1 & 10.00 & 81.00 & 46.00 & 1.22 & 6.50 & 150.00 & 2.80 & 147.20 & 0.039 & 38.90 \\
2 & 13.00 & 90.00 & 52.00 & 1.26 & 8.50 & 150.00 & 2.60 & 147.40 & 0.065 & 65.01 \\
3 & 10.00 & 87.00 & 50.00 & 1.21 & 11.00 & 150.00 & 2.40 & 147.60 & 0.078 & 77.78 \\
4 & 12.00 & 75.00 & 48.00 & 1.24 & 12.00 & 150.00 & 2.40 & 147.60 & 0.078 & 78.20 \\
5 & 14.00 & 75.00 & 48.00 & 1.26 & 10.00 & 150.00 & 2.40 & 147.60 & 0.065 & 65.17 \\
6 & 15.00 & 69.00 & 53.00 & 1.21 & 8.50 & 150.00 & 2.60 & 147.40 & 0.068 & 67.53 \\
7 & 12.50 & 80.00 & 50.00 & 1.25 & 8.00 & 150.00 & 2.80 & 147.20 & 0.057 & 56.57 \\
8 & 12.00 & 78.00 & 48.00 & 1.24 & 10.00 & 150.00 & 2.60 & 147.40 & 0.065 & 65.17 \\
9 & 13.00 & 94.00 & 46.00 & 1.22 & 8.50 & 150.00 & 2.40 & 147.60 & 0.051 & 50.87 \\
10 & 12.00 & 80.00 & 50.00 & 1.20 & 10.50 & 150.00 & 2.80 & 147.20 & 0.074 & 74.25 \\
11 & 14.00 & 75.00 & 50.00 & 1.24 & 12.50 & 150.00 & 2.60 & 147.40 & 0.088 & 88.39 \\
12 & 15.00 & 81.00 & 53.00 & 1.20 & 10.00 & 150.00 & 2.60 & 147.40 & 0.079 & 79.45 \\
13 & 13.00 & 70.00 & 46.00 & 1.24 & 9.60 & 150.00 & 2.80 & 147.20 & 0.057 & 57.46 \\
14 & 12.00 & 80.00 & 50.00 & 1.26 & 10.00 & 150.00 & 2.60 & 147.40 & 0.071 & 70.71 \\
15 & 16.00 & 64.00 & 51.00 & 1.20 & 8.30 & 150.00 & 2.40 & 147.60 & 0.061 & 61.06 \\
\hline mean & 12.90 & 78.60 & 49.40 & 1.23 & 9.59 & 150.00 & 2.59 & 147.41 & 0.066 & 66.43
\end{tabular}


Research article

Table 2: Results of Chest examination (PA) for 5-9 years

\begin{tabular}{cccccccccccc} 
S/N & Weight $(\mathrm{kg})$ & Height $(\mathrm{m})$ & $\mathrm{KV} p$ & $\mathrm{FSD}(\mathrm{m})$ & $\mathrm{mAs}$ & $\mathrm{FFD}(\mathrm{cm})$ & Thiclness $(\mathrm{cm})$ & $\mathrm{SSD}(\mathrm{cm})$ & ESD $(\mathrm{mGy})$ & ESD $(\mu \mathrm{Gy})$ \\
\hline 1 & 18.00 & 82.00 & 50.00 & 1.23 & 15.00 & 150.00 & 2.70 & 147.30 & 0.106 & 106.07 \\
2 & 21.00 & 102.00 & 54.00 & 1.26 & 14.00 & 150.00 & 2.80 & 147.20 & 0.115 & 115.47 \\
3 & 27.30 & 94.50 & 54.00 & 1.23 & 13.00 & 150.00 & 2.70 & 147.30 & 0.107 & 107.22 \\
4 & 19.00 & 90.00 & 52.00 & 1.25 & 14.00 & 150.00 & 2.60 & 147.40 & 0.107 & 107.07 \\
5 & 28.00 & 86.00 & 50.00 & 1.25 & 14.00 & 150.00 & 2.70 & 147.30 & 0.099 & 99.00 \\
6 & 22.00 & 101.50 & 50.00 & 1.23 & 13.50 & 150.00 & 2.70 & 147.30 & 0.095 & 95.46 \\
7 & 19.00 & 87.40 & 51.00 & 1.26 & 15.00 & 150.00 & 2.77 & 147.23 & 0.110 & 110.35 \\
8 & 24.00 & 98.00 & 52.00 & 1.23 & 14.00 & 150.00 & 2.80 & 147.20 & 0.107 & 107.07 \\
9 & 27.00 & 78.00 & 54.00 & 1.25 & 14.00 & 150.00 & 2.80 & 147.20 & 0.115 & 115.47 \\
10 & 18.00 & 89.00 & 51.00 & 1.25 & 15.00 & 150.00 & 2.80 & 147.20 & 0.110 & 110.35 \\
11 & 25.00 & 100.30 & 50.00 & 1.24 & 13.50 & 150.00 & 2.75 & 147.25 & 0.095 & 95.46 \\
12 & 23.00 & 92.00 & 50.00 & 1.23 & 14.50 & 150.00 & 2.70 & 147.30 & 0.103 & 102.53 \\
13 & 26.00 & 89.00 & 53.00 & 1.25 & 12.50 & 150.00 & 2.85 & 147.15 & 0.099 & 99.31 \\
14 & 19.00 & 100.80 & 51.00 & 1.26 & 14.50 & 150.00 & 2.73 & 147.27 & 0.107 & 106.67 \\
15 & 20.50 & 86.00 & 50.00 & 1.24 & 14.00 & 150.00 & 2.80 & 147.20 & 0.099 & 99.00 \\
\hline mean & 22.45 & 91.77 & 51.47 & 1.24 & 14.03 & 150.00 & 2.75 & 147.25 & 0.105 & 105.10
\end{tabular}

Table 3: Results of Chest examination (PA) for 10-17 years

\begin{tabular}{ccccccccccc} 
S/N & Weight $(\mathrm{kg})$ & Height $(\mathrm{m})$ & $\mathrm{KVp}$ & FSD $(\mathrm{m})$ & mAs & FFD $(\mathrm{cm})$ & Thickness $(\mathrm{cm})$ & SSD $(\mathrm{cm})$ & ESD $(\mathrm{mGy})$ & ESD $(\mu \mathrm{Gy})$ \\
\hline 1 & 30.00 & 138.00 & 60.00 & 1.26 & 16.00 & 150.00 & 2.90 & 147.10 & 0.163 & 162.92 \\
2 & 46.20 & 146.00 & 60.00 & 1.26 & 20.00 & 150.00 & 3.40 & 146.60 & 0.204 & 203.65 \\
3 & 32.00 & 140.00 & 70.00 & 1.24 & 18.00 & 150.00 & 3.00 & 147.00 & 0.249 & 249.47 \\
4 & 36.50 & 143.60 & 62.00 & 1.25 & 18.00 & 150.00 & 2.80 & 147.20 & 0.196 & 195.71 \\
5 & 28.00 & 143.00 & 68.00 & 1.24 & 16.00 & 150.00 & 3.20 & 146.80 & 0.209 & 209.26 \\
6 & 45.90 & 150.00 & 70.00 & 1.24 & 20.00 & 150.00 & 2.96 & 147.04 & 0.277 & 277.19 \\
7 & 57.20 & 148.00 & 63.00 & 1.27 & 20.00 & 150.00 & 3.20 & 146.80 & 0.225 & 224.52 \\
8 & 25.00 & 138.00 & 60.00 & 1.25 & 17.00 & 150.00 & 3.15 & 146.85 & 0.173 & 173.10 \\
9 & 48.70 & 145.00 & 65.00 & 1.24 & 18.00 & 150.00 & 3.05 & 146.95 & 0.215 & 215.10 \\
10 & 48.00 & 148.00 & 69.00 & 1.23 & 20.00 & 150.00 & 2.95 & 147.05 & 0.269 & 269.32 \\
11 & 28.00 & 140.00 & 60.00 & 1.25 & 16.00 & 150.00 & 2.80 & 147.20 & 0.163 & 162.92 \\
12 & 46.00 & 145.50 & 61.00 & 1.24 & 19.00 & 150.00 & 2.90 & 147.10 & 0.200 & 199.97 \\
13 & 40.00 & 151.00 & 64.00 & 1.26 & 16.00 & 150.00 & 3.00 & 147.00 & 0.185 & 185.36 \\
14 & 50.00 & 150.00 & 66.00 & 1.25 & 20.00 & 150.00 & 2.80 & 147.20 & 0.246 & 246.41 \\
15 & 52.00 & 153.00 & 68.00 & 1.23 & 20.00 & 150.00 & 3.05 & 146.95 & 0.262 & 261.57 \\
\hline mean & 40.90 & 145.27 & 64.40 & 1.25 & 18.27 & 150.00 & 3.01 & 146.99 & 0.216 & 215.76
\end{tabular}


Table 4: Results of Chest examination (PA) for 18 years and above

\begin{tabular}{ccccccccccc} 
S/N & Weight $(\mathrm{kg})$ & Height $(\mathrm{m})$ & KVp & FSD $(\mathrm{m})$ & mAs & FFD $(\mathrm{cm})$ & Thiclness $(\mathrm{cm})$ & SSD $(\mathrm{cm})$ & ESD $(\mathrm{mGy})$ & ESD $(\mu \mathrm{Gy})$ \\
\hline 1 & 78.00 & 168.00 & 70.00 & 1.26 & 20.00 & 150.00 & 3.20 & 146.80 & 0.277 \\
2 & 54.00 & 155.00 & 85.00 & 1.28 & 19.00 & 150.00 & 3.10 & 146.90 & 0.388 & 388.27 \\
3 & 42.00 & 183.00 & 53.00 & 1.23 & 21.00 & 150.00 & 2.90 & 147.10 & 0.167 & 166.85 \\
4 & 56.00 & 158.00 & 78.00 & 1.24 & 20.00 & 150.00 & 3.10 & 146.90 & 0.344 & 344.16 \\
5 & 51.00 & 173.00 & 66.00 & 1.19 & 21.50 & 150.00 & 3.20 & 146.80 & 0.265 & 264.89 \\
6 & 106.00 & 170.00 & 90.00 & 1.28 & 22.50 & 150.00 & 3.00 & 147.00 & 0.515 & 515.48 \\
7 & 94.00 & 180.00 & 60.00 & 1.20 & 20.00 & 150.00 & 3.10 & 146.90 & 0.204 & 203.65 \\
8 & 71.00 & 173.00 & 88.00 & 1.27 & 19.00 & 150.00 & 3.10 & 146.90 & 0.416 & 416.16 \\
9 & 52.00 & 147.00 & 62.00 & 1.25 & 20.00 & 150.00 & 3.10 & 146.90 & 0.217 & 217.45 \\
10 & 69.00 & 155.00 & 71.00 & 1.24 & 20.00 & 150.00 & 2.90 & 147.10 & 0.285 \\
11 & 58.00 & 168.00 & 73.00 & 1.23 & 16.00 & 150.00 & 3.00 & 147.00 & 0.241 & 285.16 \\
12 & 59.00 & 173.00 & 65.00 & 1.26 & 18.50 & 150.00 & 3.20 & 146.80 & 0.221 & 221.16 \\
13 & 65.00 & 165.00 & 60.00 & 1.28 & 18.00 & 150.00 & 3.20 & 146.80 & 0.183 & 183.28 \\
14 & 67.00 & 180.00 & 70.00 & 1.27 & 21.00 & 150.00 & 3.10 & 146.90 & 0.291 & 291.05 \\
15 & 60.00 & 155.00 & 82.00 & 1.25 & 19.00 & 150.00 & 3.10 & 146.90 & 0.361 & 361.35 \\
\hline mean & 65.47 & 166.87 & 71.53 & 1.25 & 19.70 & 150.00 & 3.09 & 146.91 & 0.292 & 291.81
\end{tabular}

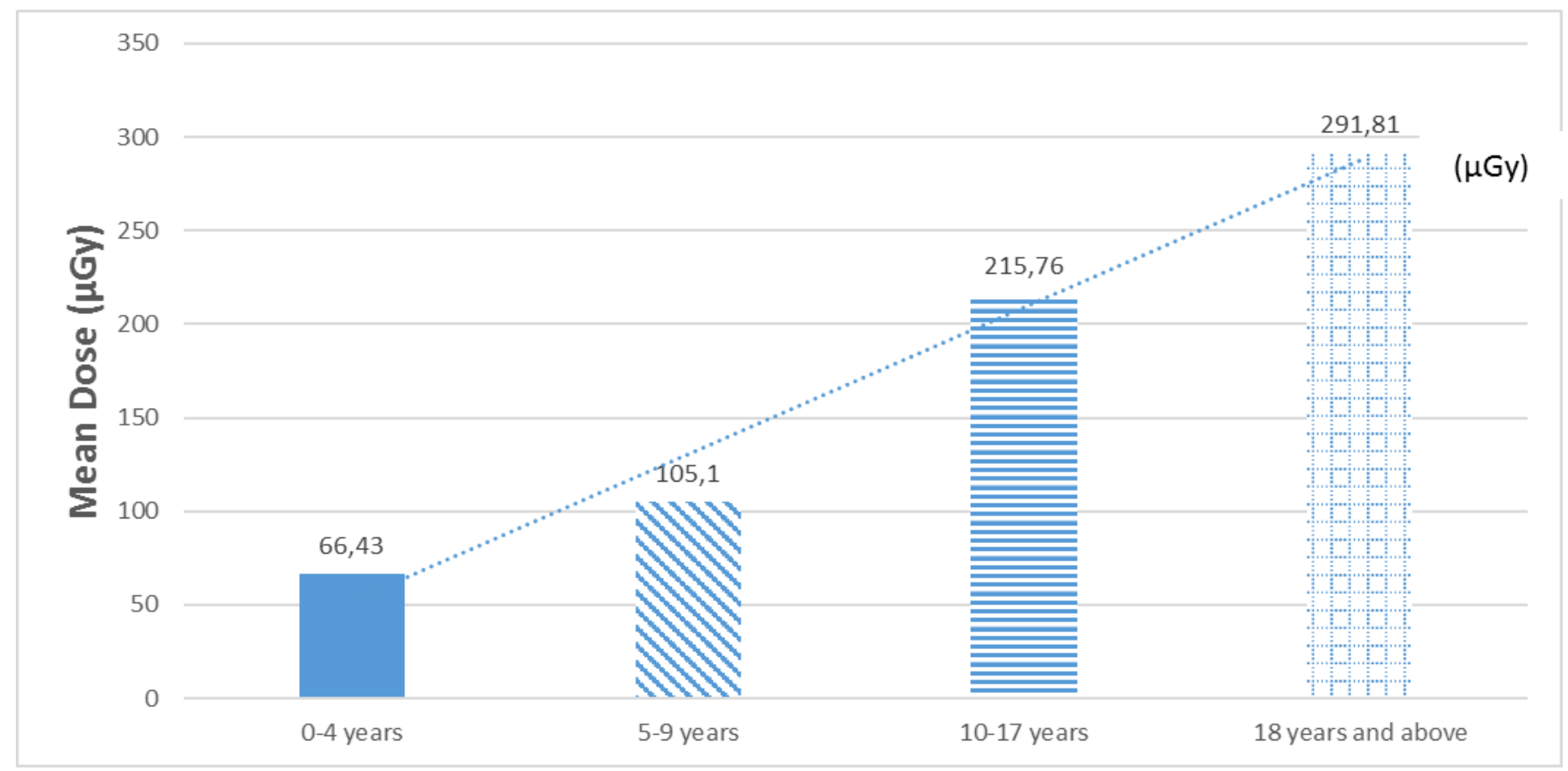

Figure. 1: Distribution of entrance skin doses during chest PA examinations across age groups. 


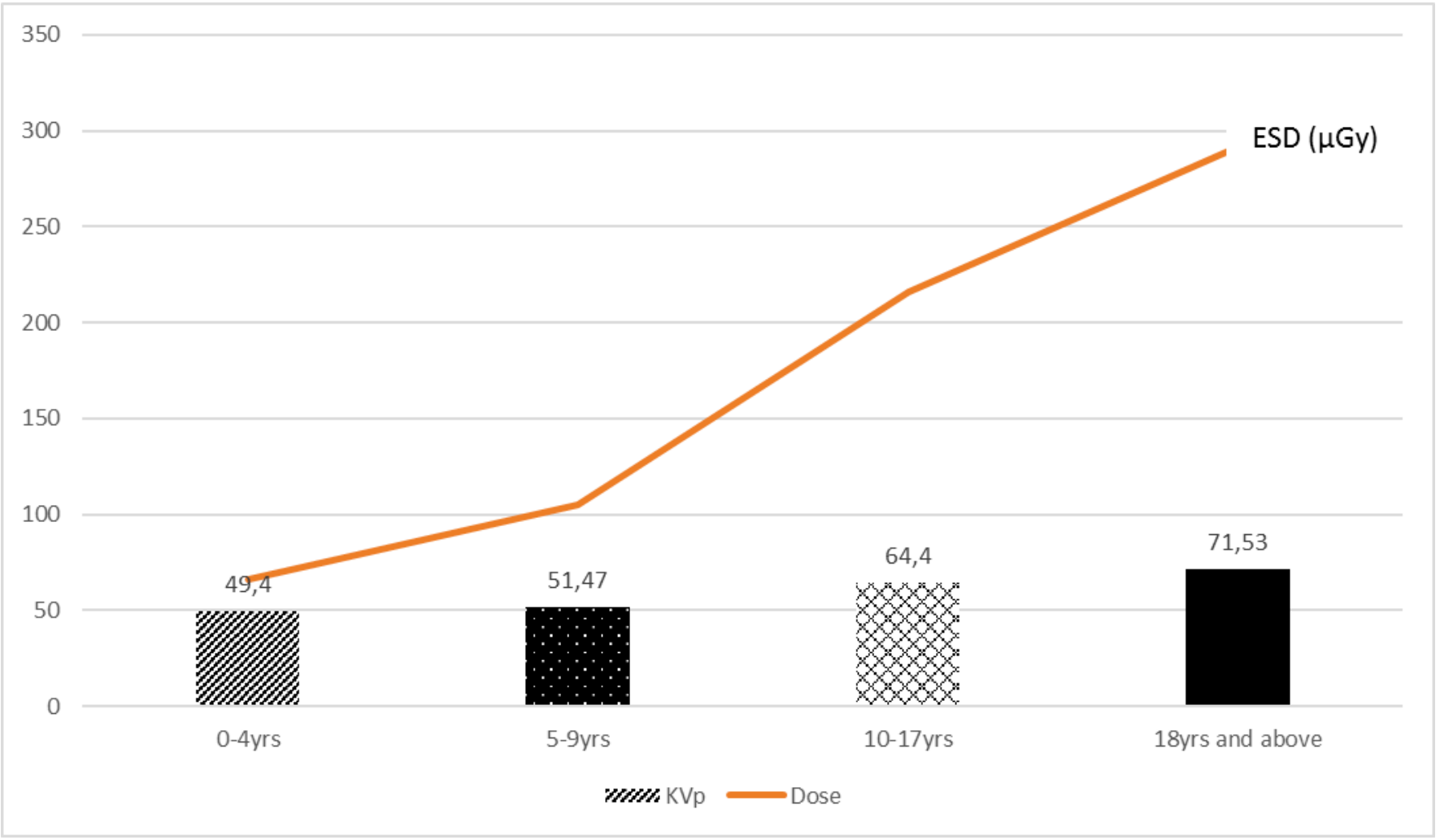

Figure. 2: Tube voltage (KVp) Vs. dose for all the age groups.

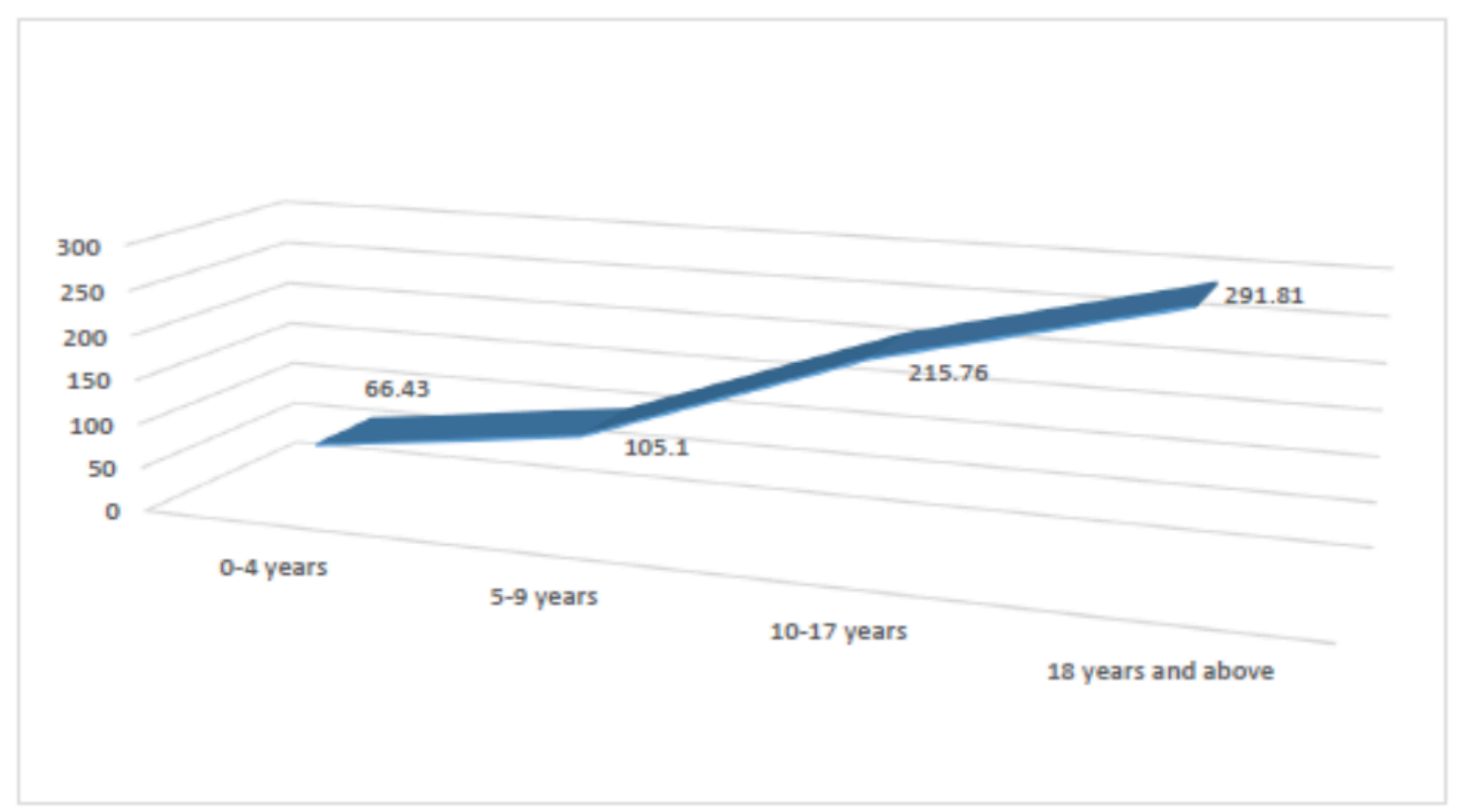

Figure. 3: Mean doses ( $\mu \mathrm{Gy}$ ) for all the age groups. 


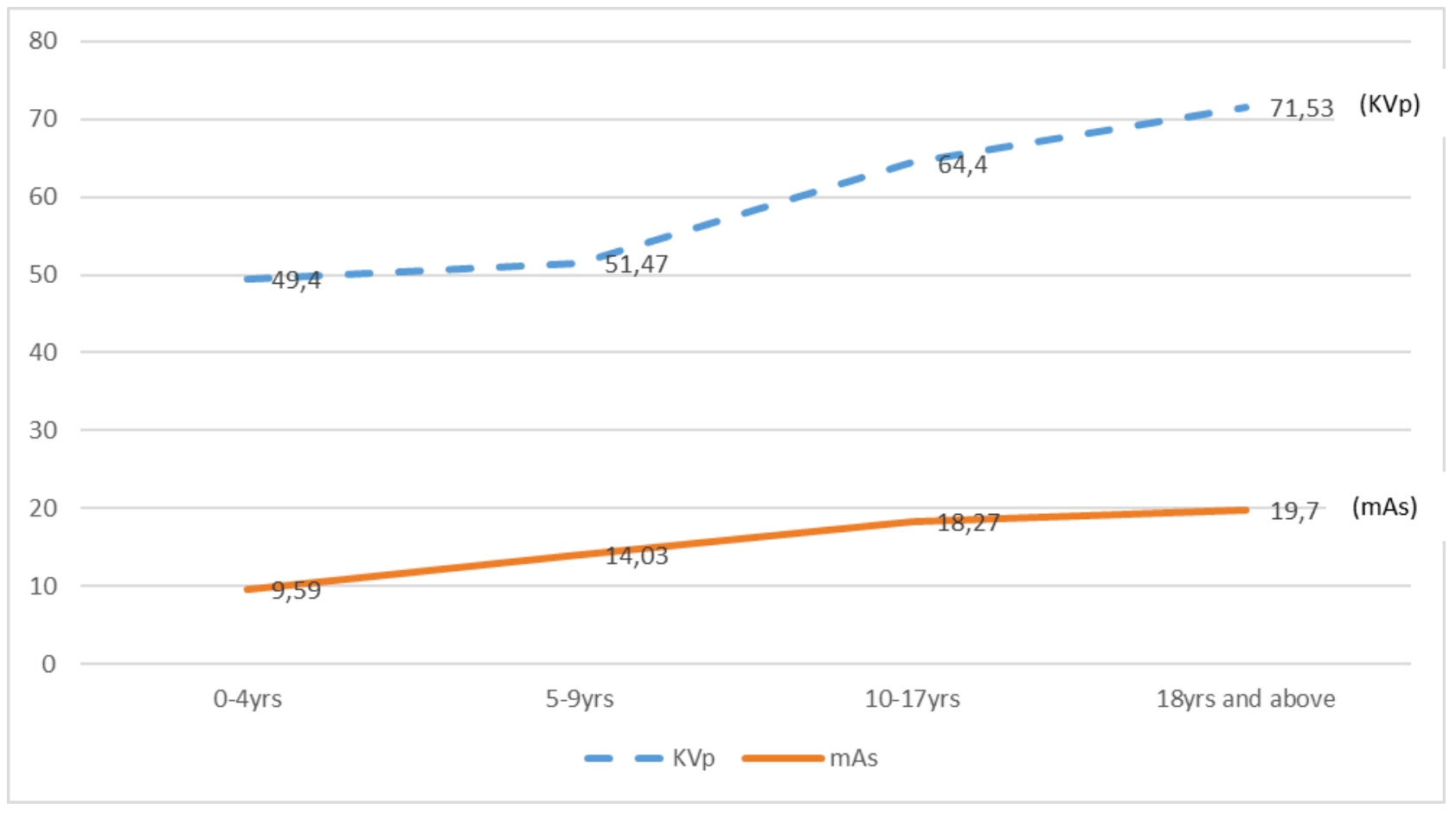

Figure. 4: Tube voltage (KVp) and $\mathrm{mAs}$ for all the age groups.

\section{Radiation Risk Assessment for the Age Groups:}

In order to assess the risk levels (i.e. probability of damage to body tissues or organs) for the age groups, the following method was adopted, appropriately measurements were made and the relevant data were acquired.

The parameter that was employed in this method of assessment is effective radiation dose (ERD) computation which is measured in Sievert $(\mathrm{Sv})$.

$E R D=(Q F) X(A R D), \quad(12)$

Where:

$Q F=$ quality factor of the X-rays used

$=\frac{\text { biological of fect of } 1 \mathrm{~Gy} \text { of radiation used }}{\text { biological of fect of } 1 \mathrm{~Gy} \text { of } 200-\mathrm{KoV} \mathrm{X} \text {-rays }}$.

$\mathrm{ARD}=$ actual radiation dose (in gray, Gy)

$=\frac{\text { energy absorbed }(J)}{\text { mass of absorber }(\mathrm{Kg})}=\frac{h \hat{\gamma}}{m_{a}}$;

$h=$ planck's constant

$\mathrm{v}=$ frequency of the X-rays used.

1 Gy of the X-rays used will cause $\left(\frac{80 \mathrm{kv}}{200 \mathrm{Kv}}=0.40\right)$ times the damage due to 1 Gy of 200-KeV X-rays. Hence, the QF of the X-rays used is 0.40 .

For each age group, six patients were randomly selected for measurements and data acquisitions.

Table 5 presents the relative logic levels of the radiation risk factor (RRF) used in categorizing the radiation levels in the patients for all the age groups. 
Table 5: Radiation Risk Assessment Table Guide [13]

\begin{tabular}{|c|l|c|l|}
\hline S/No. & Condition & Logic Level & Conclusion of Inference \\
\hline 1 & $(E R D)_{\operatorname{mm}} \geq(E R D)_{c \max }$ & 1 & Risk is high (i.e., RRF is high). \\
\hline 2 & $(E R D)_{\operatorname{mm}}<(E R D)_{c \max }$ & 0 & Risk is low (i.e., RRF is low). \\
\hline
\end{tabular}

Where:

$(E R D)_{m m}=$ mean measured ERD.

$(E R D)_{c m a x}=$ critical maximum value of ERD.

Based on this method, the experimentally calculated values of the radiation risk assessment for the age groups are presented in Table 6 .

Table 6: Radiation Risk Assessment for the Age Groups

\begin{tabular}{|c|c|c|c|c|c|c|}
\hline Age Group & $\begin{array}{c}\text { Radiation } \\
\text { QF }\end{array}$ & $\begin{array}{c}\text { ARD } \\
(\mu \mathrm{Gy})\end{array}$ & $\begin{array}{c}(\mathrm{ERD})_{\mathrm{mm}} \\
(\mu \mathrm{Gy})\end{array}$ & $\begin{array}{c}(\mathrm{ERD})_{\mathrm{cmax}} \\
(\mathrm{mGy})\end{array}$ & Observation & RRF \\
\hline 0-4 years & 0.40 & 66.43 & 26.56 & 0.11 & $(E R D)_{\operatorname{mm}} \ll(E R D)_{\text {cmax }}$ & Low $(0)$ \\
5-9 years & 0.40 & 105.10 & 42.04 & 0.12 & $(E R D)_{\operatorname{mm}} \ll(E R D)_{\text {cmax }}$ & Low $(0)$ \\
10-17 years & 0.40 & 215.76 & 86.30 & 0.22 & $(E R D)_{\operatorname{mm}} \ll(E R D)_{\text {max }}$ & Low $(0)$ \\
18 years and \\
above
\end{tabular}

Where:

$A R D=0.001^{\mathrm{hv}} / m_{a} ; m_{a}=$ mass (in Kg) of absorber of patient (values are obtained from the experimental results).

$(E R D)_{m m}=$ mean measured ERD for an age group

$=\frac{\sum_{i=1}^{N}(E R D)_{i}}{N}$

$(E R D)_{\text {cmax }}=$ critical maximum ERD that can be tolerated (for all age groups obtained from Nuclear Data-Sheets-2015).

Since $(E R D)_{m m}<(E R D)_{c \max }$ for all the age groups, it follows that for all the age groups considered, the radiation risk factor is low in each case.

\section{Conclusion}

Entrance skin dose (ESD) values for patients undergoing chest X-ray examinations at the state specialist hospital in Okitipupa have been monitored. Biographical data such as patient age, weight, height, chest thickness and machine parameters were recorded. The absorbed dose rate increases for patients as the age increases and in some cases, as the chest thickness increases. The doses reported for this present study were same with the NRPB recommendations of year 2000 of $50 \mu \mathrm{Gy}$ for new born to 1 -year-old, $70 \mu \mathrm{Gy}$ for 5 years and $120 \mu \mathrm{Gy}$ for 10 years old children.

However, other values were compared with the guidance levels set by the International regulation bodies and were found to be within safe limits. The tables and figures show that the mean doses received by patients increase with increased weights and vary with the patients' chest thicknesses. The radiation 
risk factors (RRFs) were determined for all the age groups and found to be very low.

\section{Recommendation}

The most important parameter considered by technicians is the image quality. Therefore, mAs values were normally used in order to obtain good image contrast, causing delivery of higher, avoidable dose values to patients. This should be changed so as to consider not only the image quality of the radiography diagnosis but also the dose delivery to patients, which should be maintained as low as reasonable achievable (ALARA principle). Special attention should be given to pediatric x-ray examination because pediatric patients are more radiosensitive than adult patients. Also, consistency in quality assurance program and training of personnel will go a long way in reducing radiation doses received by the patients.

\section{References:}

1. Ademola, A.K., Obed, R.I., Adejumo, C.A., Abodunrin, O.P., Alabi, O.F. and Oladapo, M. (2013). "Assessment of Entrance Skin Dose in Routine X-ray Examinations of Chest, Skull, Abdomen and Pelvis of Children in Five Selected Hospitals in Nigeria". IOSR J. of Applied Physics, 5:47-50.

2. ARPNSA (2017). "National Diagnostic Reference Level Fact Sheet". Australian Radiation Protection and Nuclear Safety Agency, Miranda: Australian Government, 2017.

3. BPDR (2017). "Basic Physics of Digital Radiography". The Patient - Wiki-books, Open Books for an Open World". En.wikibooks.org.

4. Edmonds IR (1984) Calculation of Patient Skin Dose from Diagnostic X-ray Procedure. British Journal of Radiology 57, 733-734.

5. European Commission (1996). European Guidelines on Quality Criteria for Diagnostic Radiographic Images. EC Report 16260. Luxembourg.

6. ICRP (1996). Radiological Protection and Safety in Medicine. ICRP Publication 73. Ann. 26(2).

7. ICRP (2007). Diagnosis Reference Levels in Medical Imaging: Review and Additional Advice. International Commission on Radiological Protection (ICRP), Publication 105, Section 10.

8. ICRP (2011). The International Commission on Radiological Protection. Annals of the ICRP Report on Radiological Protection in Fluoroscopically Guided Procedures Performed Outside the Imaging Department.

9. Johnson, J.C. (1997). Standard Practices in Civilian Radiation Protection. National Academy of Sciences Publication (US).

10. Marshall, G.W. and Keene, S. (2007). Radiation Safety in Modern Radiology Department: A Growing Concern. Internet Journal of Radiology; 5:3-6.

11. NRPB (2000). "Reference Doses and Patients Size in Pediatric Radiology". National Radiation Protection Board, NRPB-R318.

12. UNSCEAR (2010). United Nations; Sources and Effects of Ionizing Radiation Report.

13. European Commission (2015). General Guidelines on Risk Management in External Beam Radiotherapy. ISSN 2315-2826, Directorate D - Nuclear Safety and Fuel Cycle. 


\section{Appendix}

The standard tables on radiation doses, limits and effects are presented as follows:

Table A1: General Categories of Exposure to Radiation and Permitted Limits.

\begin{tabular}{lll}
\hline Acute: & Large dose, short time, not repeated & $0.1-0.3 \mathrm{~Sv}$ \\
Medium: & Intermediate dose, short time, repeated & $0.01-0.1 \mathrm{~Sv}$ \\
Low: & Low level, continuous & $0.01-0.1 \mathrm{mSv}$ \\
\hline
\end{tabular}

The current Canadian and American Atomic Energy Control Board limit on whole body dose rate for atomic radiation workers is $50 \mathrm{mSv} / \mathrm{a}$. the United Kingston has a limit of $15 \mathrm{mSv} / \mathrm{a}$. The current AECB limit on whole body dose rate for the general public is $5 \mathrm{mSv} / \mathrm{a}$. The lethal whole body dose from penetrating ionizing radiation (50\% probability of death in 30 days) is 2.5-3.0 Gy.

Table A2: Regulations for Maximum Permissible Dose (MPD)

Type of Exposure Maximum dose $\mathrm{mSv} / \mathrm{a}$

Occupational exposure

Annual limit

Long-term accumulation to $\mathrm{N}$ years of age

Skin

Hands

Other organs

Fertile women

Public or occasionally exposed

Students

Individuals

Emergency-life saving

Whole body

The medical effects of radiation are well established. In the case of acute or short-term doses, the observed clinical effects are the following (Table A3).

Table A3: Clinical Effects of Acute Radiation Dose

\begin{tabular}{|l|l|}
\hline Acute dose $(\mathrm{Sv})$ & Probable clinical effects \\
\hline $0-0.5$ & No observable short-term effects \\
$0.5-1.0$ & Slight blood change \\
$1-2$ & Moderate blood change, vomiting, fatigue, recovery in a few weeks \\
$2-6$ & Vomiting, severe blood change, haemorrhage and infection, loss of hair \\
$6-10$ & Recovery from 1 month to 1 year at low dose end, 20\% of survival at high end. \\
& Vomiting, loss of hair, 80-100\% likely death within two months. \\
\hline
\end{tabular}

